\title{
Computing the protein binding sites
}

\author{
Fei Guo ${ }^{1,2}$, Lusheng Wang ${ }^{2^{*}}$ \\ From 7th International Symposium on Bioinformatics Research and Applications (ISBRA'11) \\ Changsha, China. 27-29 May 2011
}

\begin{abstract}
Background: Identifying the location of binding sites on proteins is of fundamental importance for a wide range of applications including molecular docking, de novo drug design, structure identification and comparison of functional sites. Structural genomic projects are beginning to produce protein structures with unknown functions. Therefore, efficient methods are required if all these structures are to be properly annotated. Lots of methods for finding binding sites involve 3D structure comparison. Here we design a method to find protein binding sites by direct comparison of protein 3D structures.

Results: We have developed an efficient heuristic approach for finding similar binding sites from the surface of given proteins. Our approach consists of three steps: local sequence alignment, protein surface detection, and 3D structures comparison. We implement the algorithm and produce a software package that works well in practice. When comparing a complete protein with all complete protein structures in the PDB database, experiments show that the average recall value of our approach is $82 \%$ and the average precision value of our approach is also significantly better than the existing approaches.
\end{abstract}

Conclusions: Our program has much higher recall values than those existing programs. Experiments show that all the existing approaches have recall values less than 50\%. This implies that more than 50\% of real binding sites cannot be reported by those existing approaches. The software package is available at http://sites.google.com/site/ guofeics/bsfinder.

\section{Background}

Identifying the location of binding sites on proteins is of fundamental importance for a wide range of applications including molecular docking, de novo drug design, structure identification and comparison of functional sites. Structural genomic projects are beginning to produce protein structures with unknown functions. Therefore, efficient methods are required if all these structures are to be properly annotated.

Many methods have been proposed for identifying the location of binding sites on proteins. Laurie and Jackson give an energy-based method for the prediction of protein-ligand binding sites [1]. Bradford and Westhead combine a support vector machine (SVM) approach with surface patch analysis to predict protein-protein binding

\footnotetext{
* Correspondence: cswangl@cityu.edu.hk

${ }^{2}$ Department of Computer Science, City University of Hong Kong, 83 Tat

Chee Avenue, Kowloon, Hong Kong

Full list of author information is available at the end of the article
}

sites [2]. Chen et al. develop a tool, 3D-partner, for inferring interacting partners and binding models [3]. 3D-partner first utilizes IMPALA to identify homologous structures (templates) of a query protein sequence from heterodimer profile library. The sequence profiles of those templates are then used to search interacting candidates of the query from protein sequence databases by PSI-BLAST. Lo et al. develop a method for predicting helix-helix interaction from residue contacts in membrane proteins [4]. They first predict contact residues from sequences. Their relationships are further predicted in the second step via statistical analysis on contact propensities and sequence and structural information. Li $e t a l$. propose an approach for finding binding sites for groups of proteins [5]. It contains the following steps: finding protein groups as bicliques of protein-protein interaction networks (PPI), identifying conserved motifs, and searching domain-domain interaction databases. Liu et al. extend the method of Li et al. in [5] and
() Biomed Central

(c) 2012 Guo and Wang; licensee BioMed Central Ltd. This is an Open Access article distributed under the terms of the Creative Commons Attribution License (http://creativecommons.org/licenses/by/2.0), which permits unrestricted use, distribution, and reproduction in any medium, provided the original work is properly cited. 
consider comparing 3D local structures [6]. Guo and Wang identify the binding sites by finding two similar 3D substructures [7].

SiteEngine is a method that recognizes the regions on the surface of one protein that are similar to the binding sites of another. It uses geometric hashing triangles to transfer the input sites into the recognized region [8]. SuMo is a system for finding similarities in arbitrary 3D structures or substructures of proteins. It is based on a unique representation of macromolecules using selected triples of chemical groups [9]. The web server pdbFun analyzes the structure and function of proteins at the residue level [10]. When comparing a complete protein with all complete protein structures in the PDB database, experiments show that all the existing approaches have recall values less than $50 \%$ implying that more than $50 \%$ of real binding sites cannot be reported by those existing approaches.

In this paper, we design a method to recognize regions of binding sites on the proteins. It consists of three steps: local sequence alignment, protein surface detection, and $3 \mathrm{D}$ structures comparison. Experiments show that the average recall value of our approach is $82 \%$ and the average precision value of our approach is also significantly better than the existing approaches.

\section{Methods}

Given two complete protein structures, our task is to find the binding sites on the given proteins. Our method contains three steps. Step 1, we do local sequence alignment at the atom level to get the alignments of conserved regions. These alignments of conserved regions may contain some gaps. Step 2, among the conserved regions obtained in Step 1, we use the 3D structure information to identify the surface segments. Step 3, for any pair of the surface segments identified in Step 2, we compute a rigid transformation to compare the similarity of the substructures in 3D space and output the qualified pairs as binding sites.

\section{Step 1: Local sequence alignment}

In PDB format files, each residue (amino acid) is represented in the traditional order of atom records N, CA, C, $\mathrm{O}$, followed by the side chain atoms (CB, CG1, CG2 ...) in order first of increasing remoteness, and then branch. The whole protein sequence of residues can be translated into a sequence of atoms based on this representation. The sequences of binding sites on the proteins are usually conserved at the atom level. When looking at the SitesBase [11], we can see that the pair of binding sites form a conserved region that are well aligned at the atom level, where atoms of the same types are matched and all the unmatched atoms correspond to gaps. Figure 1 is the result of SitesBase for proteins 1TU4D and 5P21A.
We use the standard Smith-Waterman's local alignment algorithm [12] to find the conserved segments, where a matched pair of atoms of the same type has a score 1, a mismatched pair of atoms of different types has a score $-\infty$, a mismatch between an atom and a space has a score -2 . The local alignment algorithm can return a set of conserved segments in the alignment of the protein sequences of atoms.

We have done many experiments and found that the set of conserved segments output by the local sequence alignment algorithm always contains the pairs of binding sites in the SitesBase. The only problem is that the local sequence alignment algorithm outputs too many matched atoms. Next, we will further reduce the matched atoms. After obtaining the set of conserved segments from the local sequence alignment, we focus on the columns with identical pairs of atoms and ignore the rest of columns in the following steps.

\section{Step 2: Identifying surface segments}

Inspired by the work in [13], we propose the following method to find surface segment of proteins. First, the protein is projected onto $3 \mathrm{D}$ grid in the Euclidean space. For the grid, we use a step size of $1 \AA$. Second, grid points are marked as interior, surface or empty. A grid point is marked as protein if the point is within $2 \AA$ distance of an atom in the protein. A grid point is marked as empty if it is not protein point. A grid point is marked as interior if all its six neighbor grid points are protein points. A grid point is marked as surface if at least one of its six neighbor grid points is not protein point. An atom in the protein is a surface atom if it is within distance $1.5 \AA$ of a surface point. Figure 2 gives an example, where the dark grid points are surface points.

For a conserved segment output by the local sequence alignment algorithm, we consider all its subsegments containing at least 15 matched pairs of atoms. For such a subsegment, if both sequences on this subsegment have at least $2 / 3$ atoms as the surface atoms, we treat such a subsegment as a candidate binding site for further processing in the next step.

\section{Step 3: Computing rigid transformations to match candidate binding sites}

For any candidate binding sites obtained from Step 2, we will further test if the pair of 3D substructures can match well on such a site. Precisely, we can find the set of subsegments in a given segment with alignment $\mathcal{A}$ using the following rule: there exists a rigid transformation such that the distance between each pair of atoms in the same column of the subsegment is at most $d$, where $d$ is a parameter given by the user. A rigid transformation is a transformation for protein 3D structure in the 3D space that preserves distances between any 


\begin{tabular}{|c|c|c|c|c|c|c|c|c|c|c|c|c|c|c|c|}
\hline 1 to $4 \mathrm{D}$ & $\begin{array}{l}\mathrm{C} \\
\mathrm{E} 28\end{array}$ & $\begin{array}{l}\mathrm{O} \\
\mathrm{E} 28\end{array}$ & $\begin{array}{l}\mathrm{CA} \\
\mathrm{S} 29\end{array}$ & $\begin{array}{l}\text { C } \\
\text { S29 }\end{array}$ & $\begin{array}{l}\mathrm{O} \\
\mathrm{S} 29\end{array}$ & $\begin{array}{l}\text { CB } \\
\text { S29 }\end{array}$ & $\begin{array}{l}\mathrm{N} \\
\mathrm{A} 30\end{array}$ & $\begin{array}{l}\mathrm{CA} \\
\mathrm{A} 30\end{array}$ & $\begin{array}{l}\mathrm{C} \\
\mathrm{A} 30\end{array}$ & $\begin{array}{l}\mathrm{O} \\
\mathrm{A} 30\end{array}$ & $\begin{array}{l}\text { CB } \\
\text { A30 }\end{array}$ & $\begin{array}{l}\mathrm{N} \\
\mathrm{V} 31\end{array}$ & $\begin{array}{l}\text { CA } \\
\text { V31 }\end{array}$ & $\begin{array}{l}\mathrm{C} \\
\mathrm{V} 31\end{array}$ & $\begin{array}{l}\mathrm{O} \\
\mathrm{V} 31\end{array}$ \\
\hline $5 \mathrm{P} 21 \mathrm{~A}$ & $\begin{array}{l}\text { C } \\
\text { A } 11\end{array}$ & $\begin{array}{l}0 \\
\text { A11 }\end{array}$ & $\begin{array}{l}\mathrm{CA} \\
\mathrm{G} 12 \\
\end{array}$ & $\begin{array}{l}\mathrm{C} \\
\mathrm{G} 12\end{array}$ & & & $\begin{array}{l}\mathrm{N} \\
\mathrm{G} 13 \\
\end{array}$ & $\begin{array}{l}\mathrm{CA} \\
\mathrm{G} 13 \\
\end{array}$ & $\begin{array}{l}\mathrm{C} \\
\mathrm{G} 13 \\
\end{array}$ & $\begin{array}{l}0 \\
\text { G13 } \\
\end{array}$ & & $\begin{array}{l}\mathrm{N} \\
\mathrm{V} 14 \\
\end{array}$ & $\begin{array}{l}\mathrm{CA} \\
\mathrm{V} 14 \\
\end{array}$ & $\begin{array}{l}\text { C } \\
\text { V14 } \\
\end{array}$ & $\begin{array}{l}\mathrm{O} \\
\mathrm{V} 14 \\
\end{array}$ \\
\hline 1 tu $4 \mathrm{D}$ & $\begin{array}{l}\mathrm{CB} \\
\mathrm{V} 31\end{array}$ & $\begin{array}{l}\mathrm{CG} 2 \\
\mathrm{~V} 31\end{array}$ & $\begin{array}{l}\mathrm{N} \\
\mathrm{G} 32\end{array}$ & $\begin{array}{l}\mathrm{CA} \\
\mathrm{G} 32\end{array}$ & $\begin{array}{l}\mathrm{C} \\
\mathrm{G} 32\end{array}$ & $\begin{array}{l}\mathrm{O} \\
\mathrm{G} 32\end{array}$ & $\begin{array}{l}\mathrm{N} \\
\mathrm{K} 33\end{array}$ & $\begin{array}{l}\mathrm{CA} \\
\mathrm{K} 33\end{array}$ & $\begin{array}{l}\mathrm{C} \\
\mathrm{K} 33\end{array}$ & $\begin{array}{l}{ }^{\circ} \mathrm{CB} \\
\mathrm{K} 33\end{array}$ & $\begin{array}{l}\text { CG } \\
\text { K33 }\end{array}$ & $\begin{array}{l}\mathrm{CD} \\
\mathrm{K} 33\end{array}$ & $\begin{array}{l}\mathrm{CE} \\
\mathrm{K} 33\end{array}$ & $\begin{array}{l}\text { N } \\
\text { S34 }\end{array}$ & $\begin{array}{l}\mathrm{CA} \\
\text { S34 }\end{array}$ \\
\hline $5 \mathrm{p} 21 \mathrm{~A}$ & $\begin{array}{l}\text { CB } \\
\text { V14 }\end{array}$ & $\begin{array}{l}\text { CG2 } \\
\text { V14 }\end{array}$ & $\begin{array}{l}\mathrm{N} \\
\text { G15 }\end{array}$ & $\begin{array}{l}\text { CA } \\
\text { G15 }\end{array}$ & $\begin{array}{l}\text { C } \\
\text { G15 }\end{array}$ & $\begin{array}{l}\text { O } \\
\text { G1S }\end{array}$ & $\begin{array}{l}\mathrm{N} \\
\mathrm{K} 16\end{array}$ & $\begin{array}{l}\mathrm{CA} \\
\mathrm{K} 16\end{array}$ & $\begin{array}{l}\mathrm{C} \\
\mathrm{K} 16 \\
0\end{array}$ & $\begin{array}{l}\mathrm{CB} \\
\mathrm{K} 16 \\
0\end{array}$ & $\begin{array}{l}\text { CG } \\
\text { K16 } \\
0\end{array}$ & $\begin{array}{l}\mathrm{CD} \\
\mathrm{K} 16 \\
0\end{array}$ & $\begin{array}{l}\mathrm{CE} \\
\mathrm{K} 16 \\
0\end{array}$ & $\begin{array}{l}\mathrm{N} \\
\mathrm{S} 1 ? \\
0\end{array}$ & $\begin{array}{l}\mathrm{CA} \\
\mathrm{S} 13 \\
0\end{array}$ \\
\hline$\underline{1 \operatorname{to} 4 \mathrm{D}}$ & $\begin{array}{l}\text { C } \\
\text { S34 }\end{array}$ & $\begin{array}{l}\text { CB } \\
\text { S34 }\end{array}$ & $\begin{array}{l}\text { OG } \\
\text { S34 }\end{array}$ & $\begin{array}{l}\text { N } \\
\text { S35 }\end{array}$ & $\begin{array}{l}\mathrm{CA} \\
\text { S35 }\end{array}$ & $\begin{array}{l}\text { C } \\
\text { S35 }\end{array}$ & $\begin{array}{l}\text { CB } \\
\text { S35 }\end{array}$ & $\begin{array}{l}\text { OG } \\
\text { S35 }\end{array}$ & $\begin{array}{l}\mathrm{N} \\
\mathrm{L} 36\end{array}$ & $\begin{array}{l}\text { CA } \\
\text { G78 }\end{array}$ & $\begin{array}{l}\mathrm{C} \\
\mathrm{N} 133\end{array}$ & $\begin{array}{l}\mathrm{CB} \\
\mathrm{N} 133\end{array}$ & $\begin{array}{l}\text { CG } \\
\text { N133 }\end{array}$ & $\begin{array}{l}\text { OD1 } \\
\text { N133 }\end{array}$ & $\begin{array}{l}\text { ND2 } \\
\text { N133 }\end{array}$ \\
\hline $5 \mathrm{p} 21 \mathrm{~A}$ & $\begin{array}{l}\mathrm{C} \\
\mathrm{S} 17 \\
\end{array}$ & $\begin{array}{l}\mathrm{CB} \\
\mathrm{S} 17 \\
\end{array}$ & $\begin{array}{l}\mathrm{OG} \\
\mathrm{S} 17 \\
\end{array}$ & $\begin{array}{l}\text { N } \\
\text { A18 } \\
\end{array}$ & $\begin{array}{l}\mathrm{CA} \\
\mathrm{A} 18 \\
\end{array}$ & $\begin{array}{l}\mathrm{C} \\
\mathrm{A} 18 \\
\end{array}$ & $\begin{array}{l}\text { CB } \\
\text { A18 } \\
\end{array}$ & & & & $\begin{array}{l}\mathrm{C} \\
\mathrm{N} 116 \\
\end{array}$ & & $\begin{array}{l}\text { CG } \\
\text { N116 } \\
\end{array}$ & $\begin{array}{l}\text { OD1 } \\
\text { N116 }\end{array}$ & $\begin{array}{l}\text { ND2 } \\
\text { N116 }\end{array}$ \\
\hline$\underline{1 \operatorname{tu} 4 \mathrm{D}}$ & $\begin{array}{l}\mathrm{N} \\
\mathrm{K} 134\end{array}$ & $\begin{array}{l}\mathrm{CA} \\
\mathrm{K} 134\end{array}$ & $\begin{array}{c}\mathrm{C} \\
4 \mathrm{~K} 134\end{array}$ & $\begin{array}{l}\mathrm{O} \\
\mathrm{K} 134\end{array}$ & $\begin{array}{c}\mathrm{CB} \\
\mathrm{K} 134\end{array}$ & $\begin{array}{c}C G \\
\text { K134 }\end{array}$ & $\begin{array}{l}C D \\
K 134\end{array}$ & $\begin{array}{l}\mathrm{CE} \\
\mathrm{K} 134\end{array}$ & $\begin{array}{c}\mathrm{NZ} \\
4 \mathrm{~K} 134\end{array}$ & $\begin{array}{l}\mathrm{N} \\
\mathrm{A} 135\end{array}$ & $\begin{array}{l}\text { CB } \\
\text { D136 }\end{array}$ & $\begin{array}{l}\text { CG } \\
\text { D136 }\end{array}$ & $\begin{array}{l}\text { OD1 } \\
\text { D136 }\end{array}$ & $\begin{array}{l}\text { OD2 } \\
\text { D136 }\end{array}$ & $\begin{array}{l}\mathrm{CB} \\
\mathrm{L} 137\end{array}$ \\
\hline $5 \mathrm{p} 21 \mathrm{~A}$ & $\begin{array}{l}\mathrm{N} \\
\mathrm{K} 11 ?\end{array}$ & $\begin{array}{l}\mathrm{CA} \\
\mathrm{K} 11 ?\end{array}$ & $\begin{array}{l}\mathrm{C} \\
\mathrm{K} 11 ?\end{array}$ & & $\begin{array}{l}\mathrm{CB} \\
\mathrm{K} 117\end{array}$ & $\begin{array}{l}\text { CG } \\
\mathrm{K} 117\end{array}$ & $\begin{array}{l}\mathrm{CD} \\
\mathrm{K} 117\end{array}$ & $\begin{array}{l}\mathrm{CE} \\
\mathrm{K} 117\end{array}$ & $\begin{array}{c}\mathrm{NZ} \\
7 \mathrm{~K} 11 ?\end{array}$ & $\begin{array}{l}\mathrm{N} \\
\mathrm{C} 118\end{array}$ & & $\begin{array}{l}\text { CG } \\
\text { D119 }\end{array}$ & $\begin{array}{l}\text { OD1 } \\
\text { D119 }\end{array}$ & $\begin{array}{l}\text { OD2 } \\
\text { D119 }\end{array}$ & \\
\hline$\underline{1 \text { tu } 4 \mathrm{D}}$ & $\begin{array}{l}\mathrm{CG} \\
\mathrm{L} 137\end{array}$ & $\begin{array}{l}\text { CD1 } \\
\text { L13? }\end{array}$ & $\begin{array}{l}\text { CD2 } \\
\text { L13? }\end{array}$ & $\begin{array}{l}\mathrm{O} \\
\mathrm{T} 162\end{array}$ & $\begin{array}{l}\text { N } \\
\text { S163 }\end{array}$ & $\begin{array}{l}\mathrm{CA} \\
\mathrm{S} 163\end{array}$ & $\begin{array}{l}\mathrm{C} \\
\text { S163 }\end{array}$ & $\begin{array}{l}0 \\
\text { S163 }\end{array}$ & $\begin{array}{l}\mathrm{CB} \\
\mathrm{S} 163\end{array}$ & $\begin{array}{l}\text { OG } \\
\text { S163 }\end{array}$ & $\begin{array}{l}\mathrm{N} \\
\mathrm{A} 164\end{array}$ & $\begin{array}{l}\mathrm{CA} \\
\mathrm{A} 164\end{array}$ & $\begin{array}{l}\text { C } \\
\text { A164 }\end{array}$ & $\begin{array}{l}\mathrm{CB} \\
\mathrm{A} 164\end{array}$ & $\begin{array}{l}\mathrm{N} \\
\mathrm{K} 165\end{array}$ \\
\hline $5 \mathrm{p} 21 \mathrm{~A}$ & $\begin{array}{l}\mathrm{CD} 2 \\
\mathrm{~L} 120\end{array}$ & & & $\begin{array}{l}\mathrm{O} \\
\mathrm{T} 144\end{array}$ & $\begin{array}{l}\mathrm{N} \\
\text { S145 }\end{array}$ & $\begin{array}{l}\mathrm{CA} \\
\mathrm{S} 145\end{array}$ & $\begin{array}{l}\text { C } \\
\text { S145 }\end{array}$ & $\begin{array}{l}\mathrm{O} \\
\text { S145 }\end{array}$ & $\begin{array}{l}\text { CB } \\
\text { S } 145\end{array}$ & $\begin{array}{l}\text { OG } \\
\text { S145 }\end{array}$ & $\begin{array}{l}\mathrm{N} \\
\mathrm{A} 146\end{array}$ & $\begin{array}{l}\mathrm{CA} \\
\mathrm{A} 146\end{array}$ & $\begin{array}{l}\text { C } \\
\text { A146 }\end{array}$ & $\begin{array}{l}\mathrm{CB} \\
\mathrm{A} 146\end{array}$ & $\begin{array}{l}\mathrm{N} \\
\mathrm{K} 147\end{array}$ \\
\hline 1 tu $4 \mathrm{D}$ & $\begin{array}{l}\mathrm{CA} \\
\mathrm{K} 165\end{array}$ & $\begin{array}{l}\mathrm{CB} \\
\mathrm{K} 165\end{array}$ & $\begin{array}{l}\mathrm{CG} \\
\mathrm{K} 165\end{array}$ & $\begin{array}{l}\mathrm{CD} \\
\mathrm{K} 165\end{array}$ & $\begin{array}{l}\mathrm{CE} \\
\mathrm{K} 165\end{array}$ & $\begin{array}{l}\mathrm{NZ} \\
\mathrm{K} 165\end{array}$ & & & & & & & & & \\
\hline $5 \mathrm{p} 21 \mathrm{~A}$ & $\begin{array}{l}\mathrm{CA} \\
\mathrm{K} 14 \text { ? }\end{array}$ & $\begin{array}{l}\mathrm{CB} \\
\mathrm{K} 147\end{array}$ & $\begin{array}{l}\mathrm{CG} \\
\mathrm{K} 14 ?\end{array}$ & $\begin{array}{l}\mathrm{CE} \\
\mathrm{K} 147\end{array}$ & & & & & & & & & & & \\
\hline
\end{tabular}

Figure 1 The binding sites on 1TU4D and 5P21A.

pair of points in the structure of protein. This requires us to solve the following protein $3 \mathrm{D}$ structure matching problem:

Input: A segment with sequence alignment $\mathcal{A}$ of two proteins, where each position in the alignment has two identical atoms, the 3D coordinate of each atom in the alignment, and a threshold $d$.

Goal: Find a set of subsegments with alignment $\mathcal{A}$ such that for each output subsegment the Euclidean distance between each pair of atoms in the same column is at most $d$.

The protein 3D structure matching problem can be solved in several ways. Here we use the method in [14] which is a faster version of the method in [15] to solve the problem. The method in [14] can compute a rigid transformation such that the distance between each matched pair of atoms is at most $(1+L) d$, where $L=0.1$ is a parameter to control the precision of the transformation. This is just an approximate rigid transformation, and it is good enough in practice.

\section{Testing the overlap of the proteins in 3D space}

When computing the rigid transformation, we also require that the proteins do not overlap under the transformation. For each rigid transformation that can match the substructures of the candidate subsegment, we test if the proteins have overlap in 3D space under such a transformation as follows:

1. Construct the grid in 3D space and mark each grid point as interior, surface or empty as in Step 2 with respect to each of the given proteins.

2. Let $X$ be the number of grid points that are interior points for both proteins, $X_{1}$ and $X_{2}$ be the number of interior points of the first protein and the second protein, respectively. If $X \leq 0.05 \times \min \left\{X_{1}, X_{2}\right\}$, then we say that there is no overlap between proteins under the current 


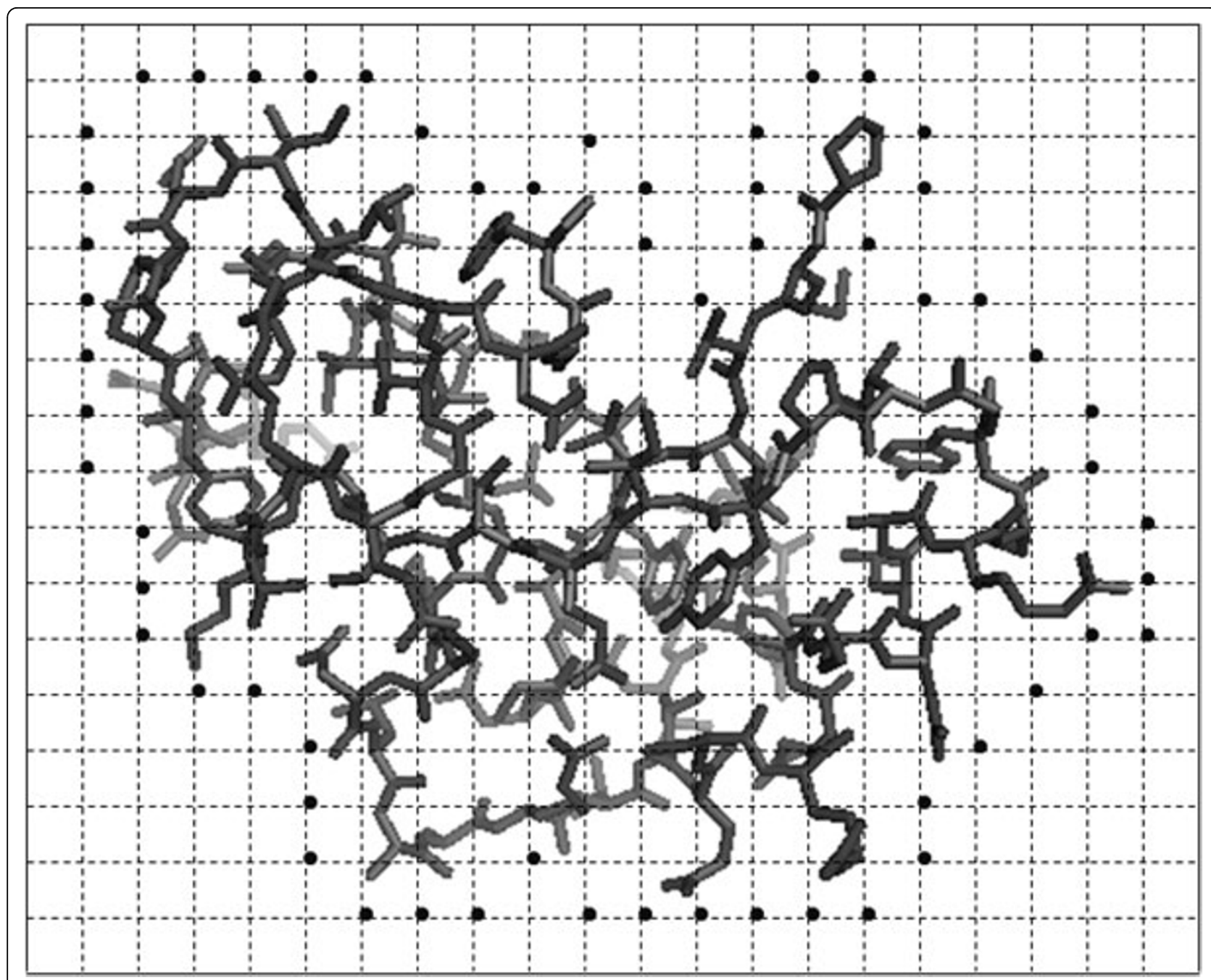

Figure 2 The surface grid points are indicated by the dark points.

rigid transformation and we output the matched substructures as the predicted binding sites.

\section{Results}

\section{Comparison with existing methods}

In this section, we compare our program BsFinder with three existing programs SiteEngine, SuMo, and pdbFun. They use different methods to predict the binding sites of given proteins. SiteEngine [16] is a method that recognizes the regions on the surface of one protein that are similar to the binding sites of another, and geometric hashing triangles are used to transfer the input sites into the recognized region [8]. SuMo [17] is a system for finding binding sites onto query structures, by comparing the structure of triplets of chemical groups against the binding sites found in PDB database [9]. The web server pdbFun [18] locates binding sites in proteins at the residue level, and it analyzes structural similarity between any pair of residue selections [10].
To compare BsFinder with the three existing systems, we use the proteins in PDB database, and select 55 proteins to compare with the whole database. Note that the Structural Classification of Proteins (SCOP) database [19] in [20] aims to provide a detailed and comprehensive description of the structural and evolutionary relationships between all proteins whose structures are known. It provides 11 classes to separate all known protein folds. Each class contains several different families. We choose 5 proteins from each class in different families such that there is only one entry from each family. Since BsFinder allows users to give the value of $d$, we set the threshold $d=1.5 \AA$ and output the matched sites with at least 15 atoms.

\section{Evaluation of prediction}

To calculate the precision and recall value for each approach, we need to know which pair of binding sites output by the programs is real. Here we look at 
SitesBase [21] in [11], which holds the set of known binding sites found in PDB. The precision value is defined as the number of sites output by the program that are confirmed in SitesBase divided by the total number of sites output by the program, where a output site is confirmed in SitesBase if at least two residues of the output sites are the same as the binding sites in SitesBase. As the sites output by SuMo are very short, the sites output by SuMo are confirmed if each one has at least one residue which is identical to that in SitesBase. Ideally, all the sites output by the program are confirmed in SitesBase, in the case, the precision value is $100 \%$. Apparently, the larger the precision value is, the better the program is. The recall value is defined as the number of sites output by the program that are confirmed in SitesBase divided by the total number of binding sites more than two complete residues for given proteins in SitesBase. If all the binding sites for given proteins in the SitesBase can be output by the program, then the recall value is $100 \%$. Again, the larger the recall value is, the better the program is.

We use the 55 selected proteins to compare with the whole PDB database. The results are shown in Table 1 . The average numbers of the sites output by BsFinder, SiteEngine, SuMo, and pdbFun are 6425, 6003, 6329, and 1936, respectively. On average, pdbFun reports the smallest number of sites and the other three systems output approximately the same number of sites. The average numbers of the confirmed sites output by BsFinder, SiteEngine, SuMo, and pdbFun are 2218, 1265,674 , and 281, respectively. See Figure 3(a).

The precision and recall values for 55 proteins output by four programs are shown in Table 1. Apparently, BsFinder has the largest precision and recall values for most of the cases. On average, the precision value of BsFinder is $34 \%$ while the precision values for SiteEngine, SuMo, and pdbFun are $21 \%, 11 \%$, and $15 \%$, respectively. The average recall value of BsFinder is $82 \%$ while the average recall values for SiteEngine, SuMo, and pdbFun are $47 \%, 25 \%$, and $11 \%$, respectively. See Figure 3(b). The value of recall is very important in practice. From the experiment results, we know that the existing programs have lower values of recall.

The possible reasons that our method can get better results might be (1) we use the surface information, (2) we look at the similarity of two local 3D substructures in terms of rigid transformation while the previous methods use triples of atoms or pairs of amino acids and (3) the volumes of the protein molecules are considered when the rigid transformation is computed.

\section{Comparison of running time}

To compare the running time of different programs, we use a Pentium(R) 4 (CPU of $2.40 \mathrm{GHz})$ to run all four programs. Based on 55 selected proteins, the average running times of BsFinder, SiteEngine, SuMo, and pdbFun for comparing each given protein with the whole PDB database are roughly 50 minutes, 70 minutes, 30 minutes, and 5 minutes, respectively. See Table 2. Thus, BsFinder is the second slowest program. However, it is still faster than SiteEngine which has the highest average values of precision and recall among the three existing programs.

\section{Performance of programs for different families}

To see the performance of programs for different protein families, we look at three different families (G proteins family in P-loop folds, PYP-like family in Profilin-like folds, and FAD-linked reductases family in FAD/NAD (P)-binding folds) and select five proteins from each family. The average numbers of matched sites output by BsFinder for three families are 7680, 5289, and 7892, respectively. The average numbers of confirmed sites for three families are 3487,1132 , and 4138 , respectively. The average precision values for three families are $45 \%, 21 \%$ and $53 \%$, respectively. The average recall values for three families are $94 \%, 60 \%$ and $96 \%$, respectively. The results are shown in Figure 4.

\section{$G$ proteins family in P-loop folds}

We select 5 proteins (1A2B, 1CXZ, 1DPF, 1FTN, 1S1C) from $\mathrm{G}$ proteins family in P-loop folds. The results are shown in Table 3. The precision values of BsFinder (48\%, $46 \%, 43 \%, 42 \%$ and $47 \%$ ) are larger than those of other three programs. The recall values of BsFinder (95\%, 93\%, $92 \%, 91 \%$ and $99 \%$ ) are more than $90 \%$, while the recall values of the other three programs are almost less than $40 \%$.

\section{PYP-like family in Profilin-like folds}

We select 5 proteins (1D7E, 1F9I, 1KOU, 1NWZ, 2PHY) from PYP-like family in Profilin-like folds. The results are shown in Table 4. The precision values of BsFinder $(17 \%, 18 \%, 24 \%, 25 \%$ and $21 \%)$ are similar to those of the other three programs. The recall values of BsFinder (58\%, $64 \%, 59 \%, 63 \%$ and $57 \%$ ) are larger than that of the other three programs.

FAD-linked reductases family in FAD/NAD(P)-binding folds

We select 5 proteins $(1 \mathrm{~B} 4 \mathrm{~V}, 1 \mathrm{~B} 8 \mathrm{~S}, 1 \mathrm{COY}, 1 \mathrm{IJH}, 3 \mathrm{COX})$ from FAD-linked reductases family in FAD/NAD(P)-binding folds. The results are shown in Table 5 . The precision values of BsFinder $(54 \%, 52 \%, 53 \%, 53 \%$ and $54 \%$ ) are all more than $50 \%$. The recall values of BsFinder (97\%, 96\%, $96 \%, 96 \%$ and $98 \%$ ) are very close to $100 \%$.

A Case: We compare two proteins $4 \mathrm{VHBA}$ and 1CQXA. The cartoon version of the protein 3D structures are shown in Figure 5, and the matched parts of structures are shown as the sticks fashion. BsFinder finds a rigid transformation that matches residues 84-86 from 4VHBA to residues 84-86 from 1CQXA, residues 
Table 1 Comparison of BsFinder, SiteEngine, SuMo, and pdbFun on 55 proteins.

\begin{tabular}{|c|c|c|c|c|c|c|c|c|}
\hline & \multicolumn{2}{|c|}{ BsFinder } & \multicolumn{2}{|c|}{ SiteEngine } & \multicolumn{2}{|c|}{ SuMo } & \multicolumn{2}{|c|}{ pdbFun } \\
\hline & number $^{\dagger}$ & ratio(\%) $)^{\ddagger}$ & number $^{\dagger}$ & ratio(\%) & number $^{\dagger}$ & ratio(\%) & number $^{\dagger}$ & ratio(\%) \\
\hline $1 C 52$ & $5937 / 1583$ & $27 / 73$ & $4798 / 1212$ & $25 / 56$ & $1014 / 159$ & $16 / 8$ & $2621 / 627$ & $24 / 29$ \\
\hline $8 G S S$ & $6111 / 3243$ & $53 / 95$ & $4702 / 1918$ & $41 / 57$ & $4698 / 1603$ & $34 / 48$ & $2704 / 951$ & $35 / 28$ \\
\hline $256 B$ & $7834 / 3102$ & $40 / 89$ & $3982 / 1410$ & $35 / 41$ & $664 / 100$ & $15 / 3$ & $798 / 221$ & $28 / 7$ \\
\hline $8 I C K$ & $8984 / 3758$ & $42 / 97$ & $8165 / 1848$ & $23 / 48$ & $9398 / 1526$ & $16 / 40$ & $2208 / 372$ & $17 / 10$ \\
\hline $4 \mathrm{VHB}$ & $7122 / 2299$ & $32 / 78$ & $3750 / 855$ & $23 / 30$ & $1500 / 167$ & $11 / 6$ & $1014 / 251$ & $25 / 9$ \\
\hline $2 \mathrm{BPV}$ & $6210 / 1309$ & $21 / 85$ & $4689 / 717$ & $15 / 47$ & $842 / 66$ & $8 / 5$ & $1230 / 151$ & $12 / 10$ \\
\hline 2RTO & $5540 / 2463$ & $44 / 69$ & $3612 / 1350$ & $37 / 38$ & $2542 / 871$ & $34 / 24$ & $1744 / 173$ & $10 / 5$ \\
\hline 2TRM & $4528 / 1268$ & $28 / 53$ & $6984 / 1107$ & $16 / 46$ & 10126/919 & $9 / 38$ & $2348 / 331$ & $14 / 14$ \\
\hline 2XAT & $6041 / 2783$ & $46 / 72$ & $4506 / 1046$ & $23 / 27$ & $4721 / 856$ & $18 / 22$ & $1963 / 230$ & $12 / 6$ \\
\hline UנJU & $5074 / 936$ & $18 / 79$ & $5685 / 616$ & $11 / 53$ & $9785 / 381$ & $4 / 33$ & $5328 / 429$ & $8 / 37$ \\
\hline $4 \mathrm{FX} 2$ & $5603 / 2667$ & $48 / 68$ & $3318 / 1064$ & $32 / 28$ & $1878 / 583$ & $31 / 15$ & $1833 / 439$ & $24 / 12$ \\
\hline $5 P 21$ & $7179 / 3401$ & $47 / 87$ & $6017 / 1998$ & $33 / 52$ & $7556 / 1702$ & $23 / 44$ & $2097 / 659$ & $31 / 17$ \\
\hline 2DUB & $8681 / 2764$ & $32 / 89$ & $7226 / 1734$ & $24 / 57$ & $2641 / 473$ & $18 / 16$ & $2673 / 531$ & 20/18 \\
\hline 3MAN & $7469 / 3536$ & $47 / 91$ & $8974 / 2102$ & $23 / 55$ & $9487 / 1627$ & $17 / 43$ & $2371 / 983$ & $42 / 26$ \\
\hline 6DFR & $7541 / 3621$ & $48 / 93$ & $8054 / 2479$ & $31 / 64$ & $3682 / 877$ & $24 / 23$ & $2318 / 670$ & 29/18 \\
\hline $1 \mathrm{~J} 6 \mathrm{~W}$ & $8543 / 2361$ & $28 / 88$ & $4812 / 1324$ & $28 / 54$ & $2762 / 314$ & $12 / 13$ & $1133 / 276$ & $25 / 11$ \\
\hline 3PYP & $5733 / 3347$ & $58 / 87$ & $3043 / 932$ & $31 / 25$ & $1841 / 529$ & $29 / 14$ & $1713 / 358$ & $21 / 9$ \\
\hline 1E1V & $8719 / 2148$ & $24 / 85$ & $6704 / 1064$ & $16 / 48$ & $8505 / 882$ & $11 / 39$ & 1943/195 & $10 / 9$ \\
\hline $1 \mathrm{OIY}$ & $8452 / 2981$ & $35 / 92$ & $8104 / 1884$ & $23 / 59$ & $8441 / 1121$ & $13 / 35$ & $1844 / 280$ & $15 / 9$ \\
\hline $3 B \cup 4$ & $1407 / 874$ & $62 / 84$ & $3916 / 948$ & $24 / 38$ & $3945 / 599$ & $15 / 24$ & $1089 / 48$ & $4 / 2$ \\
\hline $1 \mathrm{~T} 9 \mathrm{G}$ & $7092 / 2526$ & $36 / 84$ & $8927 / 1714$ & $19 / 58$ & $9590 / 1073$ & $11 / 36$ & $2243 / 318$ & $14 / 11$ \\
\hline 7CAT & $6813 / 1564$ & $23 / 87$ & $7241 / 1483$ & $21 / 83$ & $14407 / 875$ & $6 / 49$ & $2375 / 376$ & $16 / 21$ \\
\hline $1 J \times 4$ & $5294 / 497$ & $9 / 94$ & $5576 / 314$ & $6 / 60$ & $5637 / 198$ & $4 / 38$ & $1843 / 65$ & $4 / 12$ \\
\hline $1 \mathrm{CY} 6$ & $5791 / 477$ & $8 / 95$ & $8485 / 326$ & $4 / 66$ & $11855 / 220$ & $2 / 44$ & $2793 / 85$ & $3 / 17$ \\
\hline 1SK6 & $3267 / 457$ & $14 / 82$ & $9713 / 368$ & $4 / 75$ & $17100 / 345$ & $2 / 70$ & $2094 / 79$ & $4 / 16$ \\
\hline $1 \mathrm{H} 2 \mathrm{~S}$ & $8437 / 2263$ & $27 / 95$ & $3567 / 967$ & $27 / 41$ & $3079 / 497$ & $16 / 21$ & $2912 / 211$ & $8 / 9$ \\
\hline 1DDT & $8071 / 1921$ & $24 / 89$ & $7446 / 1324$ & $18 / 65$ & $11301 / 904$ & $8 / 45$ & $3428 / 162$ & $5 / 8$ \\
\hline $1 \cup 19$ & $8186 / 3523$ & $43 / 92$ & $9795 / 2057$ & $21 / 54$ & $11298 / 1629$ & $14 / 43$ & $2619 / 508$ & $19 / 13$ \\
\hline 1PPJ & $6638 / 377$ & $6 / 94$ & $9657 / 332$ & $4 / 83$ & $10634 / 146$ & $2 / 37$ & $3509 / 59$ & $2 / 15$ \\
\hline 1NTM & $6263 / 916$ & $15 / 87$ & $6640 / 421$ & $6 / 43$ & $13164 / 362$ & $3 / 37$ & $3357 / 48$ & $2 / 5$ \\
\hline 7INS & $6327 / 3155$ & $50 / 82$ & $5827 / 1750$ & $30 / 46$ & $682 / 38$ & $6 / 1$ & $169 / 47$ & $28 / 2$ \\
\hline $1 \mathrm{KIO}$ & $8011 / 3356$ & $42 / 91$ & $7502 / 2014$ & $27 / 55$ & $8999 / 1601$ & $18 / 43$ & $876 / 240$ & $27 / 7$ \\
\hline 1PTR & $5386 / 1696$ & $31 / 67$ & $5503 / 1349$ & $25 / 54$ & $1849 / 296$ & $16 / 12$ & $743 / 94$ & $13 / 4$ \\
\hline $1 \mathrm{GMN}$ & $7970 / 3474$ & $44 / 88$ & $7706 / 2014$ & $26 / 53$ & $5955 / 1053$ & $18 / 27$ & $733 / 261$ & $36 / 7$ \\
\hline $1 \mathrm{~F} 4 \mathrm{~L}$ & $8445 / 1964$ & $23 / 94$ & $8683 / 1459$ & $17 / 71$ & $13102 / 1078$ & $8 / 52$ & $3199 / 435$ & $14 / 21$ \\
\hline $1 \mathrm{G} 9 \mathrm{~B}$ & $8738 / 2779$ & $32 / 89$ & $5786 / 1959$ & $34 / 68$ & $3542 / 382$ & $11 / 13$ & $4354 / 837$ & $19 / 29$ \\
\hline $1 \mathrm{JSH}$ & $3183 / 1365$ & $43 / 45$ & $4251 / 726$ & $17 / 24$ & $8483 / 1246$ & $15 / 41$ & $1735 / 537$ & $31 / 18$ \\
\hline $1 \mathrm{MG} 1$ & $8162 / 1220$ & $15 / 91$ & $9897 / 952$ & $10 / 74$ & $11225 / 573$ & $5 / 44$ & 2559/191 & $7 / 15$ \\
\hline $1 S 1 C$ & $7999 / 3827$ & $48 / 97$ & $7460 / 2382$ & $32 / 62$ & $6037 / 1299$ & $22 / 34$ & $1898 / 532$ & $28 / 14$ \\
\hline $1 \mathrm{KWX}$ & $7995 / 2236$ & $28 / 95$ & $6022 / 1765$ & $30 / 75$ & $5255 / 452$ & $9 / 19$ & $1831 / 201$ & $11 / 9$ \\
\hline $11 \mathrm{ZL}$ & $8155 / 3676$ & $45 / 96$ & 7196/1637 & $23 / 43$ & $2632 / 477$ & $18 / 15$ & $928 / 244$ & $26 / 7$ \\
\hline 1DWL & $6558 / 3201$ & $49 / 83$ & $3695 / 1269$ & $35 / 33$ & $246 / 45$ & $18 / 1$ & $317 / 100$ & $32 / 3$ \\
\hline 1FFX & $6770 / 902$ & $13 / 87$ & $7392 / 422$ & $6 / 41$ & $16061 / 469$ & $3 / 45$ & $2699 / 76$ & $3 / 7$ \\
\hline $3 \mathrm{LDH}$ & $6086 / 2762$ & $45 / 75$ & $6013 / 1890$ & $32 / 52$ & $11994 / 1464$ & $12 / 40$ & $1924 / 321$ & $17 / 9$ \\
\hline $2 \mathrm{YHX}$ & $8213 / 2737$ & $33 / 91$ & $8279 / 1642$ & $20 / 54$ & $9127 / 1186$ & $13 / 39$ & $2250 / 169$ & $8 / 6$ \\
\hline $1 \mathrm{GO9}$ & $5165 / 2661$ & $52 / 67$ & $3571 / 1210$ & $34 / 31$ & $30 / 1$ & $3 / 1$ & $359 / 135$ & $38 / 4$ \\
\hline $1 \mathrm{HTH}$ & $3321 / 1636$ & $49 / 42$ & $2147 / 896$ & $42 / 23$ & $55 / 7$ & $13 / 1$ & $58 / 20$ & $34 / 1$ \\
\hline $1 \mathrm{LXF}$ & $6121 / 1034$ & $17 / 78$ & $4831 / 731$ & $15 / 55$ & $2945 / 145$ & $5 / 11$ & $733 / 25$ & $4 / 2$ \\
\hline 2PRG & $6147 / 832$ & $14 / 86$ & $6298 / 718$ & $12 / 74$ & $6151 / 190$ & $3 / 20$ & $1873 / 71$ & $4 / 8$ \\
\hline $1 \mathrm{H} 2 \mathrm{~K}$ & $964 / 43$ & $4 / 94$ & $2779 / 26$ & $2 / 58$ & $8038 / 108$ & $1 / 40$ & $2017 / 18$ & $1 / 40$ \\
\hline
\end{tabular}


Table 1 Comparison of BsFinder, SiteEngine, SuMo, and pdbFun on 55 proteins. (Continued)

\begin{tabular}{|c|c|c|c|c|c|c|c|c|}
\hline $1 \mathrm{G} 8 \mathrm{X}$ & $6989 / 3605$ & $52 / 91$ & $8935 / 2029$ & $23 / 54$ & $16085 / 2318$ & $14 / 62$ & $5733 / 797$ & $14 / 21$ \\
\hline $1 J Y 4$ & $4207 / 2171$ & $52 / 56$ & $2678 / 756$ & $28 / 20$ & $129 / 35$ & $27 / 1$ & $105 / 49$ & $5 / 1$ \\
\hline $1 \mathrm{~K} 09$ & $3123 / 638$ & $20 / 82$ & $1201 / 291$ & $24 / 38$ & $123 / 4$ & $3 / 1$ & $97 / 16$ & $16 / 2$ \\
\hline $1 \mathrm{ABZ}$ & $2825 / 2432$ & $86 / 63$ & $1354 / 717$ & $53 / 19$ & $44 / 1$ & $2 / 1$ & 255/93 & $36 / 3$ \\
\hline 1L6X & $8142 / 3627$ & $45 / 96$ & $7036 / 2059$ & $29 / 55$ & $5128 / 1005$ & $20 / 27$ & $858 / 355$ & $41 / 10$ \\
\hline
\end{tabular}

${ }^{\dagger}$ The first number is the number of output sites reported by the program, the second number is the number of confirmed sites reported by the program;

${ }^{\ddagger}$ The first number is the precision value (\%) for the program, the second number is the recall value (\%) for the program;

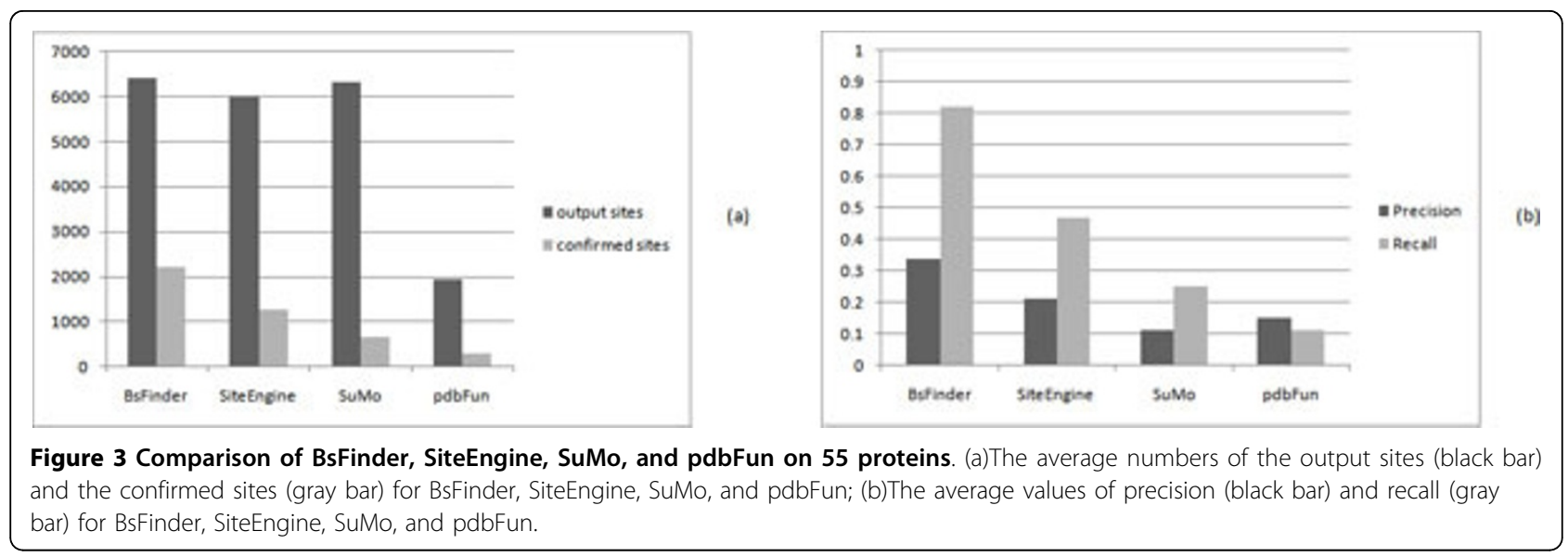

95-100 from 4VHBA to residues 95-100 from 1CQXA, and residues 125-128 from 4VHBA to residues 125-128 from 1CQXA. See Figure 6. The three pairs of matched sites are confirmed in SitesBase. Note that these three pairs can be matched under one rigid transformation simultaneously.

\section{Searching similar binding sites}

BsFinder can use a binding site to search the similar sites in the protein structures database. SiteEngine can search a given functional site on a large set of complete protein structures. SuMo can search for the given 3D site of interest among the structures of the PDB. PAST [22] is a web service based on an adaptation of the generalized suffix tree and relies on a linear representation of the protein backbone [23]. PAST can find the functional sites from the protein structures database similar to the given binding site.

We randomly select the 100 binding sites with different types from the SitesBase and search the whole PDB

Table 2 Comparison of four programs.

\begin{tabular}{llll}
\hline & Running Time & Precision & Recall \\
\hline BsFinder & 50 minutes & $34 \%$ & $82 \%$ \\
SiteEngine & 70 minutes & $21 \%$ & $47 \%$ \\
SuMo & 30 minutes & $11 \%$ & $25 \%$ \\
pdbFun & 5 minutes & $15 \%$ & $11 \%$ \\
\hline
\end{tabular}

database. The average numbers of the sites output by BsFinder, SiteEngine, SuMo, and PAST are 274, 266, 399 , and 281, respectively. The average numbers of the confirmed sites output by BsFinder, SiteEngine, SuMo, and PAST are 106, 73, 72, and 58, respectively. See Figure $7(\mathrm{a})$. BsFinder finds a relatively smallest number of output sites, and the number of confirmed sites output by BsFinder is the biggest. Apparently, BsFinder has the largest precision and recall values for most of the cases. On average, the precision value of BsFinder is $39 \%$ while the precision values for SiteEngine, SuMo, and PAST are $27 \%, 22 \%$, and $24 \%$, respectively. The average recall value of BsFinder is $86 \%$ while the average recall values for SiteEngine, SuMo, and PAST are 58\%, $51 \%$, and $45 \%$, respectively. See Figure 7 (b).

\section{Discussion}

\section{The gaps in binding sites}

In the first step of our algorithm, we do sequence alignment where each letter is an atom. This allows the matched sites to have some missed atoms, and each missed atom represents one gap in the binding sites. Step 1 is very important for predicting binding sites on proteins. Among the output sites, 67127 of them do not contain any gap, 63593 contain one gap, 77725 contain two gaps, 81259 contain three gaps, 38863 contain four gaps, 21198 contain five gaps and 3533 contain more than five gaps. The gap distribution of the confirmed 

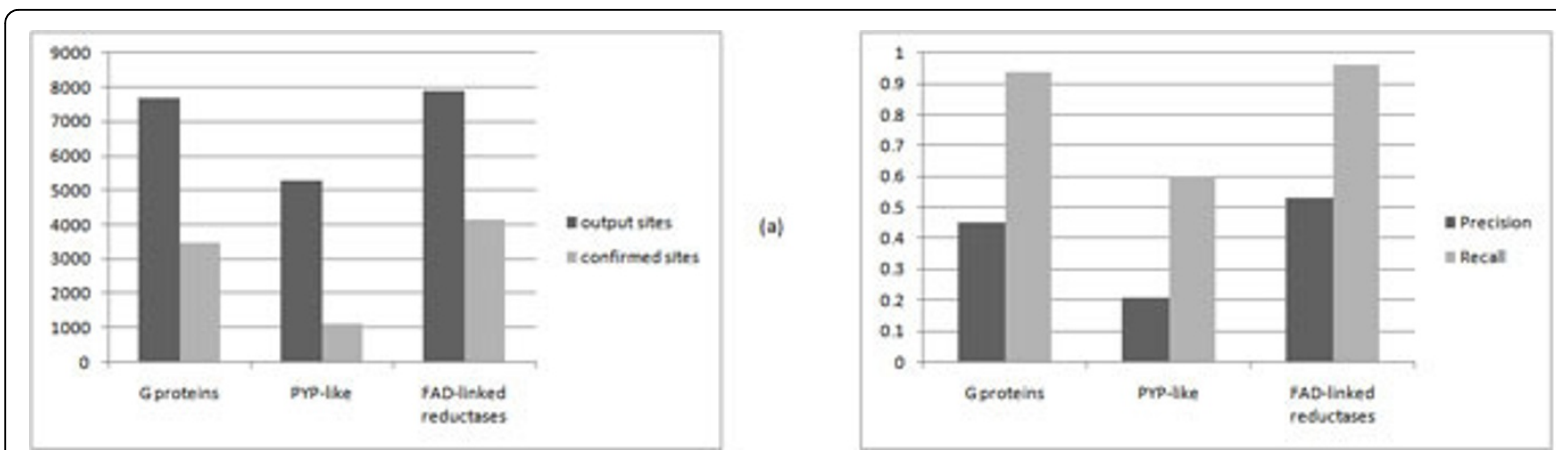

(b)

Figure 4 Results of BsFinder on three different families. (a)The average numbers of the output sites (black bar) and the confirmed sites (gray bar) for three different families; (b)The average values of precision (black bar) and recall (gray bar) for three different families.

Table 3 Comparison of the four programs on G proteins family in P-loop folds.

\begin{tabular}{|c|c|c|c|c|c|c|c|c|}
\hline & \multicolumn{2}{|c|}{ BsFinder } & \multicolumn{2}{|c|}{ SiteEngine } & \multicolumn{2}{|c|}{ SuMo } & \multicolumn{2}{|c|}{ pdbFun } \\
\hline & number $^{\dagger}$ & ratio(\%) $)^{\ddagger}$ & number $^{\dagger}$ & ratio(\%) $)^{\ddagger}$ & number $^{\dagger}$ & ratio(\%) $)^{\ddagger}$ & number $^{\dagger}$ & ratio(\%) ${ }^{\ddagger}$ \\
\hline $1 \mathrm{~A} 2 \mathrm{~B}$ & $7601 / 3647$ & $48 / 95$ & $6579 / 1717$ & $26 / 40$ & $6375 / 1209$ & $19 / 29$ & $1787 / 381$ & $21 / 9$ \\
\hline $1 C X Z$ & $7832 / 3602$ & $46 / 93$ & $7425 / 1480$ & $20 / 35$ & $8388 / 1433$ & $18 / 34$ & $2696 / 403$ & $15 / 10$ \\
\hline $1 \mathrm{DPF}$ & $7537 / 3241$ & 43/92 & $5975 / 1343$ & $23 / 34$ & $4702 / 1029$ & $22 / 26$ & $1993 / 365$ & $18 / 10$ \\
\hline 1FTN & $7435 / 3121$ & $42 / 91$ & $7147 / 1471$ & $21 / 35$ & $8599 / 1328$ & $16 / 31$ & $2232 / 414$ & $19 / 11$ \\
\hline $1 \mathrm{S1C}$ & $7995 / 3827$ & $47 / 99$ & $7460 / 1382$ & $19 / 36$ & $6037 / 1299$ & $22 / 34$ & $1898 / 532$ & $28 / 14$ \\
\hline
\end{tabular}

${ }^{\top}$ The first number is the number of output sites reported by the program, the second number is the number of confirmed sites reported by the program;

${ }^{\ddagger}$ The first number is the precision value (\%) for the program, the second number is the recall value (\%) for the program;

Table 4 Comparison of the four programs on PYP-like family in Profilin-like folds.

\begin{tabular}{|c|c|c|c|c|c|c|c|c|}
\hline & \multicolumn{2}{|c|}{ BsFinder } & \multicolumn{2}{|c|}{ SiteEngine } & \multicolumn{2}{|c|}{ SuMo } & \multicolumn{2}{|c|}{ pdbFun } \\
\hline & number $^{\dagger}$ & ratio $(\%)^{\ddagger}$ & number $^{\dagger}$ & ratio(\%) $)^{\ddagger}$ & number $^{\dagger}$ & ratio $(\%)^{\ddagger}$ & number $^{\dagger}$ & ratio(\%) ${ }^{\ddagger}$ \\
\hline 1D7E & $4845 / 834$ & $17 / 58$ & $5017 / 698$ & $14 / 48$ & $2582 / 173$ & $7 / 13$ & $223 / 33$ & $15 / 3$ \\
\hline 1F9l & $5771 / 1068$ & $18 / 64$ & $5680 / 740$ & $13 / 44$ & $3405 / 224$ & $7 / 14$ & $203 / 13$ & $7 / 1$ \\
\hline $1 \mathrm{KOU}$ & $5352 / 1297$ & $24 / 59$ & $4521 / 896$ & $20 / 41$ & $2421 / 264$ & $11 / 13$ & $916 / 80$ & $9 / 4$ \\
\hline $1 N W Z$ & $5027 / 1279$ & $25 / 63$ & $5497 / 914$ & $17 / 45$ & $2096 / 243$ & $12 / 13$ & $206 / 23$ & $12 / 2$ \\
\hline $2 \mathrm{PHY}$ & $5451 / 1189$ & $21 / 57$ & $4014 / 821$ & $20 / 39$ & $3178 / 285$ & $9 / 14$ & $208 / 15$ & $8 / 1$ \\
\hline
\end{tabular}

${ }^{\dagger}$ The first number is the number of output sites reported by the program, the second number is the number of confirmed sites reported by the program;

${ }^{\ddagger}$ The first number is the precision value (\%) for the program, the second number is the recall value (\%) for the program;

Table 5 Comparison of the four programs on FAD-linked reductases family in FAD/NAD(P)-binding folds.

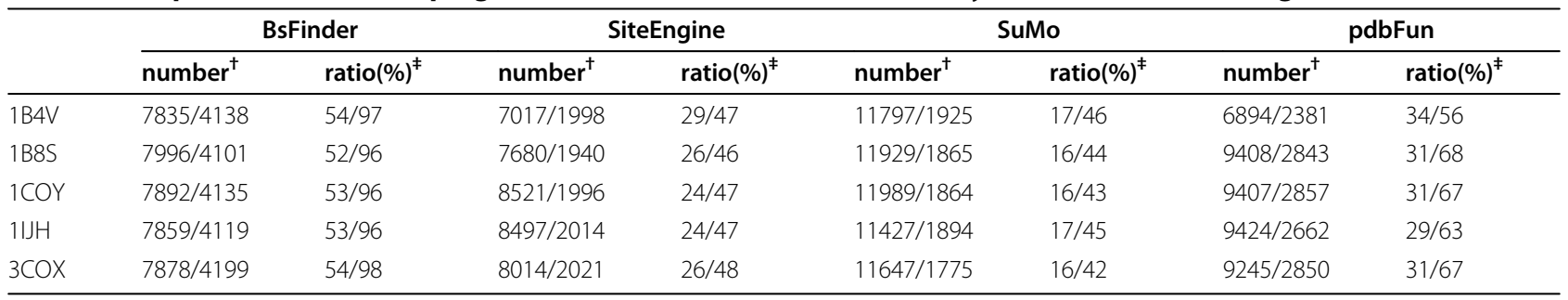

${ }^{\dagger}$ The first number is the number of output sites reported by the program, the second number is the number of confirmed sites reported by the program;

${ }^{\ddagger}$ The first number is the precision value (\%) for the program, the second number is the recall value (\%) for the program; 


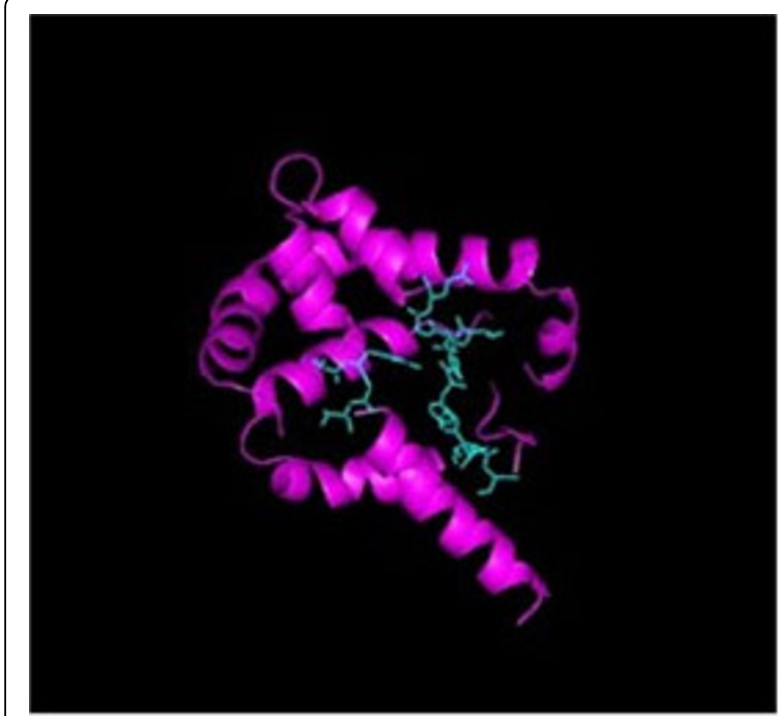

(a)

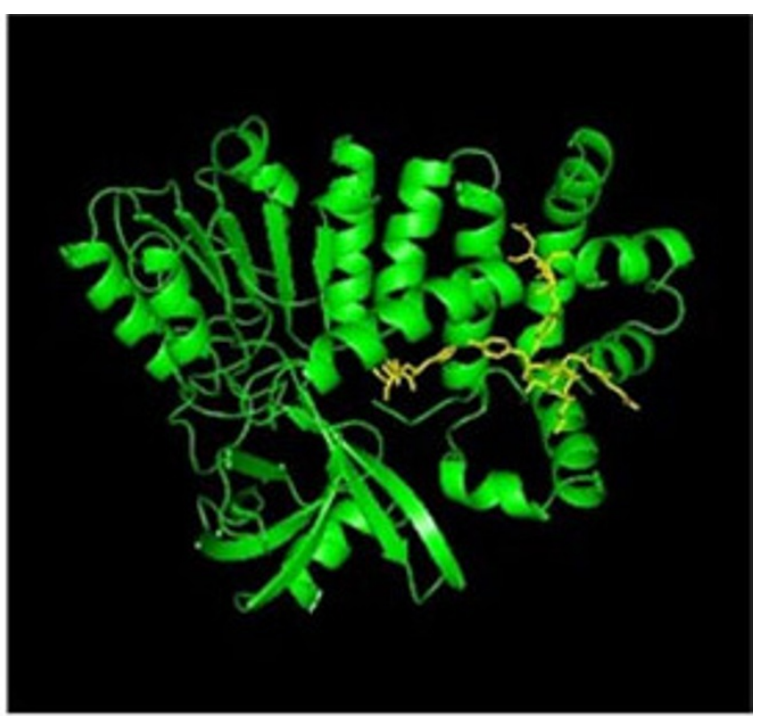

(b)

Figure 5 The 3D structures of proteins 4VHBA (a) and 1CQXA (b).

sites are 18285 (no gap), 19504 (one gap), 26809 (two gaps), 26809 (three gaps), 15847 (four gaps), 12197 (five gaps) and 2452 (more than five gaps). The confirmed sites have higher proportion of the four or more gaps among all output sites reported by BsFinder.

\section{The power of surface detection}

In Step 2 of our algorithm, we identify the surface atoms in the given proteins and rule out the substructures in which less than $2 / 3$ of atoms are the surface atoms for further calculation of the rigid transformation. To demonstrate the effect of Step 2, we compare the final version of BsFinder with the version without Step 2. By adjusting the parameters, the final version of BsFinder has improved precision value while the recall value remains essentially unchanged. The average precision values for BsFinder without Step 2 and the final version of BsFinder are $29 \%$ and $34 \%$, respectively. The average recall values for BsFinder without Step 2 and the final version of BsFinder are $83 \%$ and $82 \%$, respectively. Therefore, by doing Step 2 the precision value can be improved by about $5 \%$. This is a significant improvement.

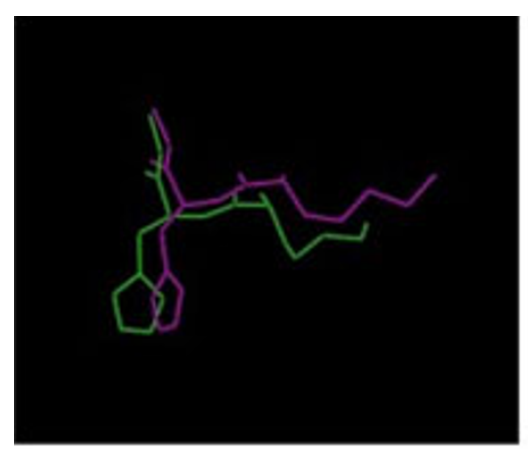

(a)

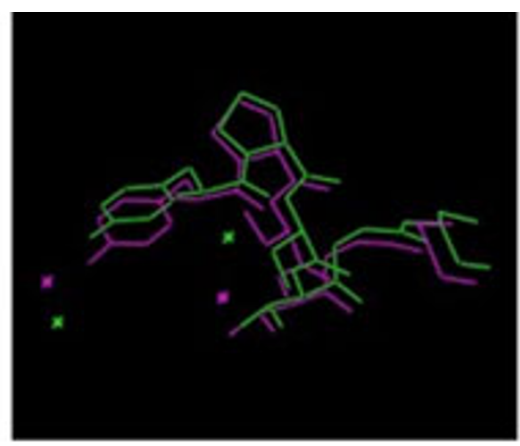

(b)

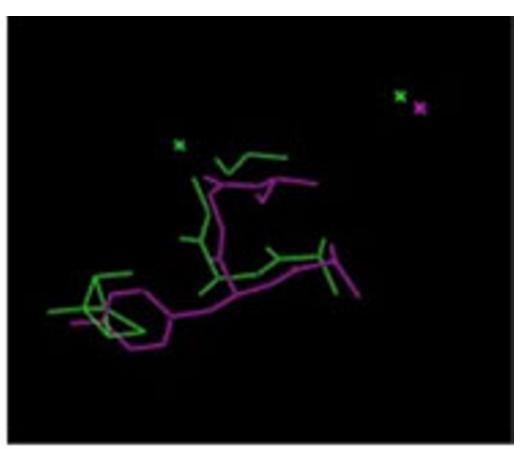

(c)

Figure 6 The similar sites for 4VHBA and 1CQXA predicted by BsFinder. (a)residues 84-86 from 4VHBA and residues 84-86 from 1CQXA; (b) residues 95-100 from 4VHBA and residues 95-100 from 1CQXA; (c) residues 125-128 from 4VHBA and residues 125-128 from 1CQXA. 


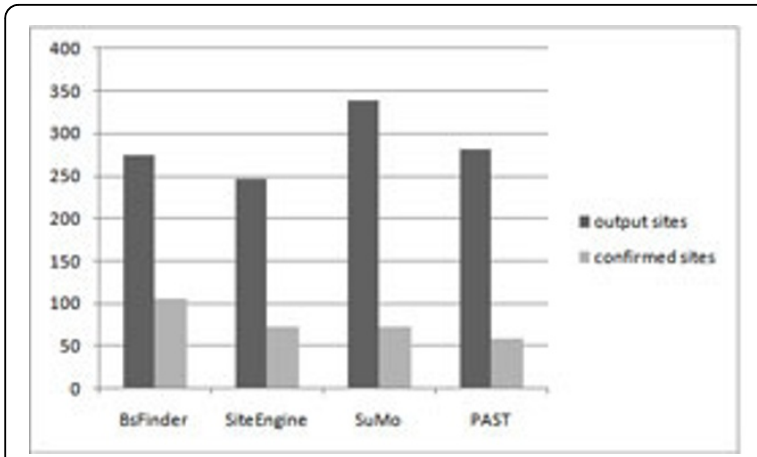

(a)

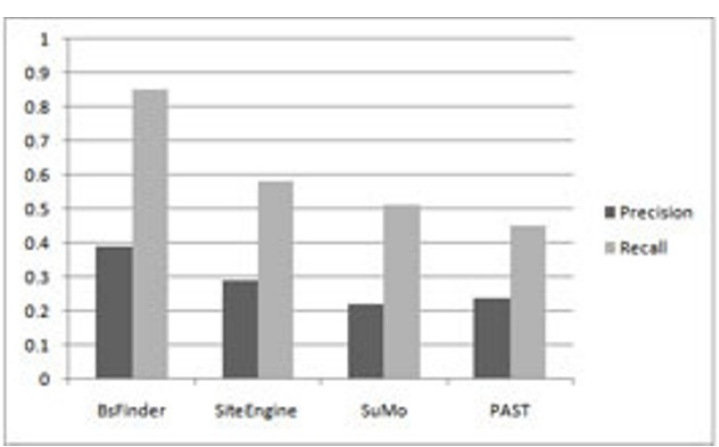

(b]

Figure 7 Comparison of BsFinder, SiteEngine, SuMo, and PAST on 100 sites. (a)The average numbers of the output sites (black bar) and the confirmed sites (gray bar) for BsFinder, SiteEngine, SuMo, and PAST; (b)The average values of precision (black bar) and recall (gray bar) for BsFinder, SiteEngine, SuMo, and PAST.

\section{Conclusions}

We have developed a program for finding binding sites on the given proteins. Our method uses the 3D structure information to detect the similar surface regions. Experiments show that our program outperforms all existing programs.

\section{Acknowledgements}

This article has been published as part of BMC Bioinformatics Volume 13 Supplement 10, 2012: "Selected articles from the 7th International Symposium on Bioinformatics Research and Applications (ISBRA'11)". The full contents of the supplement are available online at http://www. biomedcentral.com/bmcbioinformatics/supplements/13/S10. This work is supported by a grant from the Research Grants Council of the Hong Kong Special Administrative Region, China [Project No. CityU 121608].

\section{Author details}

'School of Computer Science and Technology, Shandong University, Jinan 250101, Shandong, China. ${ }^{2}$ Department of Computer Science, City University of Hong Kong, 83 Tat Chee Avenue, Kowloon, Hong Kong.

\section{Authors' contributions}

FG is in charge of the software package development and experiment design. LW is in charge of algorithm design and manuscript preparation. All authors read and approved the final manuscript.

\section{Competing interests}

The authors declare that they have no competing interests.

Published: 25 June 2012

\section{References}

1. Laurie AT, Jackson RM: Q-SiteFinder: an energy-based method for the prediction of protein-ligand binding sites. Bioinformatics 2005, 21:1908-1916.

2. Bradford JR, Westhead DR: Improved prediction of protein-protein binding sites using a support vector machines approach. Bioinformatics 2005, 21:1487-1494.

3. Chen YC, Lo YS, Hsu WC, Yang JM: 3D-partner: a web server to infer interacting partners and binding models. Nucleic Acids Res 2007, 35 : W561-W567.

4. Lo A, Chiu YY, Rodland EA, Lyu PC, Sung TY, Hsu WL: Predicting helix-helix interactions from residue contacts in membrane proteins. Bioinformatics 2008, 25:996-1003.

5. Li H, Li J, Wong L: Discovering motif pairs at interaction sites from protein sequences on a proteomewide scale. Bioinformatics 2006, 22:989-996.
6. Liu X, Li J, Wang L: Modeling protein interacting groups by quasibicliques: complexity, algorithm and application. IEEE/ACM Trans Comp Biol Bioinf 2010, 7:354-364

7. Guo F, Li SC, Wang L: Protein-protein binding sites prediction by 3D structural similarities. J Chem Inf Model 2011, 51:3287-3294.

8. Shulman-Peleg A, Nussinov R, Wolfson HJ: Recognition of functional sites in protein structures. J Mol Biol 2004, 339:607-633.

9. Jambon M, Andrieu O, Cornbet C, Deléage G, Delfaud F, Geourion C: The SuMo server: 3D search for protein functional sites. Bioinformatics 2005, 21:3929-3930.

10. Ausiello G, Zanzoni A, Peluso D, Via A, Helmer-Citterich M: pdbFun: mass selection and fast comparison of annotated PDB residues. Nucleic Acids Res 2005, 33:W133-W137.

11. Gold ND, Jackson RM: SitesBase: a database for structure-based proteinligand binding site comparisons. Nucleic Acids Res 2006, 34(Suppl 1): D231-D234.

12. Smith TF, Waterman MS: Identification of common molecular subsequences. J Mol Biol 1981, 147:195-197.

13. Huang B, Schröder M: LIGSITEE ${ }^{\text {cSC }}$ predicting ligand binding sites using the connolly surface and degree of conservation. BMC Struct Biol 2006, 6:19-29.

14. Guo F, Wang L, Yang Y, Lin G: Efficient algorithms for 3D protein substructure identification. The International Conference on Bioinformatics and Biomedical Engineering: 18-20 June 2010; Chendu 2010, 1-4.

15. Li SC, Bu D, Xu J, Li M: Finding largest well-predicted subset of protein structure models. In Combinatorial Pattern Matching, of Lecture Notes in Computer Science. Volume 5029. Springer Berlin/Heidelberg;Ferragina P, Landau G 2008:44-55.

16. SiteEngine. [http://bioinfo3d.cs.tau.ac.il/SiteEngine/].

17. SuMo. [http://sumo-pbil.ibcp.fr/cgi-bin/sumo-welcome].

18. pdbFun. [http://pdbfun.uniroma2.it].

19. SCOP database. [http://scop.mrc-Imb.cam.ac.uk/scop/index.html].

20. Murzin G, Brenner E, Hubbard T, Chothia C: SCOP: a structural classification of proteins database for the investigation of sequences and structures. J Mol Biol 1995, 247:536-540.

21. SitesBase. [http://www.modelling.leeds.ac.uk/sb/].

22. PAST. [http://past.in.tum.de/].

23. Täubig H, Buchner A, Griebsch J: PAST: fast structure-based searching in the PDB. Nucleic Acids Res 2006, 34:W20-W23.

\section{doi:10.1186/1471-2105-13-S10-S2}

Cite this article as: Guo and Wang: Computing the protein binding sites. BMC Bioinformatics 2012 13(Suppl 10):S2. 